\title{
Aggressive Versus Conservative Fluid Treatment for Acute Pancreatitis in Adult Patients: A Meta-Analysis of 3,127 Cases
}

\author{
Jiyang Liao \\ Shenzhen Hospital of Integrated Traditional Chinese and Western Medicine \\ Yang Zhan \\ The Acupuncture Rehabilitation Clinical College of Guangzhou University of Chinese Medicine \\ Huachu Wu \\ Shenzhen Hospital of Integrated Traditional Chinese and Western Medicine \\ Zhijun Yao \\ Shenzhen hospital of Integrated traditional chinese and western medicine \\ Xian Peng \\ shenzhen hospital of integrated traditional chinese and western medicine \\ Jianbo Lai ( $\nabla$ sxszxyjhyylaijianbo@outlook.com ) \\ Shenzhen Hospital of Intergrated Traditional Chinese and Western Medicine https://orcid.org/0000-0002-2790-7468
}

\section{Research}

Keywords: Aggressive fluid treatment, Acute pancreatitis, Mortality, Adverse events, Meta-analysis

Posted Date: April 28th, 2021

DOI: https://doi.org/10.21203/rs.3.rs-452485/v1

License: @ (1) This work is licensed under a Creative Commons Attribution 4.0 International License. Read Full License 


\section{Abstract}

Background: The advantages of aggressive fluid treatment (AFT) compared to conservative fluid treatment (CFT) within $24 \mathrm{~h}$ for acute pancreatitis (AP) remain controversial in adult patients. A meta-analysis was undertaken to investigate whether aggressive strategies are more beneficial.

Methods: We searched (on February 1, 2021) PubMed, Embase, and the Cochrane Library for eligible trials that assessed the two therapies and performed a meta-analysis. The primary endpoint was in-hospital mortality. Secondary outcomes were adverse events (e.g., renal failure and pancreatic necrosis) within $24 \mathrm{~h}$ of treatment.

Results: Five randomized controlled trials (RCTs) and 8 observational studies involving 3,127 patients were identified. There was a significant difference in in-hospital mortality for AFT compared to CFT (OR, 1.66; $P=0.0001)$. The incidences of renal failure (OR, 2.38; $P<0.00001)$ and pancreatic necrosis $(\mathrm{OR}, 2.34 ; P<0.0001)$ were similar and significantly different between the two groups. Patients aged $>50$ years had a potentially higher utilization of mechanical ventilation and incidence of respiratory failure (OR, 4.88; $P$ $<0.00001$ ). Persistent organ failure, systemic inflammatory response syndrome (SIRS) and length of hospital stay did not differ significantly between the two groups. Sensitivity analysis identified two significant changes: one in persistent SIRS (OR, 2.37; $P=$ $0.02)$ in patients aged $>50$ years and one in the overall incidence of persistent organ failure $(\mathrm{OR}, 1.81 ; P=0.02)$.

Conclusions: Compared to CFT, AFT increases in-hospital mortality and the incidence of renal failure, pancreatic necrosis and respiratory failure with relatively strong evidence.

\section{Background}

Acute pancreatitis (AP) is an inflammatory disease of the pancreas that ranges from a mild self-limited disease to a severe lifethreatening condition and is associated with a hospital mortality rate of $15 \%$ [1]. According to the updated Atlanta classification, there are two stages (early and late) that comprise three categories identified as mild, moderate, or severe[2]. Distant organs are commonly affected through a myriad of disturbances involving hyperinflammatory factors, injury to the vascular endothelium and redistribution of fluid as AP progresses[3].

Fluid administration for AP has gained worldwide attention among healthcare providers in the last 10 years. It is considered the cornerstone of early treatment of AP[4,5]. Despite efforts to investigate the advantages of aggressive fluid therapy (AFT), which prior guidelines recommended[5, 6], AFT remains controversial. Guidelines recommend aggressive hydration with an infusion rate of 250$500 \mathrm{ml}$ per hour or $5-10 \mathrm{ml}$ per kilogram per hour to maintain intravenous volume or stable hemodynamics[2, 4]. Nevertheless, these strategies were mainly based on expert opinion[7, 8], nonhuman studies[9, 10] and limited clinical studies[11, 12].

A number of studies comparing AFT and conservative fluid therapy (CFT) have been reported[12-20], and the advantages of AFT are difficult to discern due to limited sample sizes and conflicting results. Conversely, some trials[16, 17, 21-23] demonstrated that AFT may be associated with higher mortality or a greater incidence of adverse events. Recently, Gad et al.[24] performed a meta-analysis to investigate the efficiency and safety of AFT; however, there were some deficiencies in the pooled data due to duplicate studies and the inclusion of abstract data, which makes it difficult to assess the quality of the studies. They might overestimate the safety of AFT, even though the primary outcome is not significantly different. Therefore, we performed this meta-analysis to pool the available data and evaluate the efficiency, safety and potential advantage of CFT versus AFT.

\section{Methods}

\section{Search Strategy and Study Selection}

Studies were obtained from the electronic databases PubMed, Embase, and the Cochrane Library. Searches were restricted to human studies and English-language publications. The following MeSH terms and combinations thereof were searched in "Title/Abstract": lactate ringer's, pancreatitis, and fluid therapy (detailed search strategy is shown in Additional file 1: Table S1). Additionally, the electronic search was supplemented with manual screening of the citation lists of all retrieved studies to broaden the search. When multiple studies reported duplicate data or the same population, the most recent or complete data were included. Before performing this meta-analysis, a priori analysis of the motivation and inclusion criteria of the identified studies was conducted; some studies 
that investigated the influence of fluid type, especially for lactated ringer's solution, were also appropriate for inclusion in the present study. Therefore, the MeSH term lactated ringer's solution and combinations of the individual words were added to our electronic search. The meta-analysis was performed in accordance with the Preferred Reporting Items for Systematic Reviews and Metaanalyses (PRISMA) guidelines for systematic reviews and meta-analyses[25]. The latest search was performed on February 1, 2021.

All comparative trials that compared AFT with CFT, had at least one of the following comparable outcomes and enrolled adult patients with AP, were included. AFT was defined as fluid administration at a rate greater than $10 \mathrm{ml} / \mathrm{kg} / \mathrm{h}$ or $250 \mathrm{ml} / \mathrm{h}$ for the first 24 h. Alternatively, with significant variability in the medical record over time and difficulty with retrieving data on fluid volume (FV) every hour per kilogram from a case, patients receiving $\mathrm{FV}>4,000 \mathrm{ml}$ or more than $1 / 3$ of the total $72 \mathrm{~h} F \mathrm{~F}$ within the first $24 \mathrm{~h}$ in observational studies were also considered to have fulfilled the definition of AFT. Meanwhile, fluid therapy at a lower rate or FV than AFT was defined as CFT. Trials in which differentiation between aggressive and conservative fluid administration was not clearly predefined were excluded, as were trials relevant to patients undergoing fluid resuscitation for AP induced by endoscopic retrograde cholangiopancreatography (ERCP) or treated perioperatively. Editorials, letters, review articles, conference abstracts, case reports and animal experiments were not included.

\section{Data Extraction}

Extractable data from the included trials were summarized individually by two of the authors (Zhan and Wu). Any discrepancies were resolved by the adjudicative senior authors (Liao and Lai).

The following data were extracted from the included studies: first author, year of publication, study design, characteristics of patients, inclusion and exclusion criteria, matching criteria, and number of enrolled cases for AFT and CFT. In-hospital mortality was regarded as the primary safety outcome. Secondary outcomes comprised the posttreatment incidence of persistent systemic inflammatory response syndrome (SIRS), pancreatic necrosis, persistent organ failure, renal failure, respiratory failure, and length of hospital stay (LOS). In addition to the primary endpoints, all eligible data were obtained within the first $24 \mathrm{~h}$.

\section{Quality Assessment and Statistical Analysis}

Trials were assessed using the Grading of Recommendations Assessment, Development, and Evaluation (GRADE) system to rate the level of evidence[26] with the GRADE profiler (GRADEpro, version 3.6). With respect to the quality of evidence, the included studies were classified separately as RCTs and observational studies into 4 categories as follows: very low, low, moderate, or high.

To assess risk of bias, the Cochrane Collaboration tool was used to assess RCTs, and the Newcastle-Ottawa scale (NOS) was used to assess observational studies. The risk of bias in RCTs was rated according to seven factors: random sequence generation, allocation concealment, blinding of participants and personnel, blinding of outcome assessment, incomplete outcome data, selective reporting, and other bias. To evaluate the dynamic change influenced by the complex intervention, blinding of patients and clinicians was extremely difficult and generally not feasible, and prior to this study, we determined that in-hospital mortality was less prone to be influenced by the absence of blinding. Trials were regarded as having a high risk of bias if at least one of the factors, other than blinding, was judged as high risk. The details of the quality assessment for the observational trials were summarized according to three factors: method of patient selection, comparability of study groups, and assessment of exposure. A score of 0-9 was allocated (as stars) to each observational study, and studies achieving seven or more stars were considered to be of high quality.

Data were combined for meta-analysis using Review Manager version 5.3, and the statistical tests were two-sided. The odds ratios (ORs) for dichotomous variables or weighted mean differences (WMDs) for continuous variables were calculated using the chisquare test with significance set at $P<0.05$. Pooled data were estimated with $95 \%$ confidence intervals (Cls). Statistical heterogeneity was quantified using the $R^{2}$ statistic, with the level of significance set at $R>40 \%$. If the heterogeneity was considered to be substantial, we performed the analysis with a random-effects model; otherwise, a fixed-effects model was used. Additionally, continuous data were presented as median and range values, and standard deviations (SDs) were calculated using the technique described by Hozo et al[27]. Prespecified subgroup analyses were performed to examine the safety of AFT compared to CFT with respect to the average age of patients. To test the robustness of the outcomes, sensitivity analysis was performed by omitting one trial at a time and analyzing the remaining trials. Trials with events in both arms were included. Funnel plots were used to screen for potential publication bias.

\section{Results}


Thirteen studies[12-20, 28-31] published from 2009 to 2020 that included 3,127 patients fulfilled the selection criteria and were included in the final meta-analysis (Fig. 1). Analysis was performed on 1,472 patients treated with AFT and 1,655 patients treated with CFT. An expanded search of the reference lists of the included studies and reviews did not yield any additional studies to evaluate. Some overlap in patients was potentially present in two trials[15, 17]; however, a discrepancy between the study period and endpoints was displayed as well, and both studies were therefore included in the final analysis.

\section{Characteristics and Quality Assessment of the Included Studies}

The study characteristics are shown in Table 1 . Among the 5 included RCTs[12, 13, 15, 17, 28], 3[12, 13, 28] were judged to be of high methodological quality (Additional file 1: Fig. S1) and had similar therapeutic protocols for fluid rate (FR) that were adjusted for the patient's weight. The remaining $2 \operatorname{RCTs}[15,17]$ were judged to be of low quality with a high risk of bias in terms of selective reporting and other bias (Additional file 1: Fig. S1). These 2 studies presented a high risk of bias due to a lack of conflict of interest statement, although the protocols were supported by academic findings, and unclear definitions of outcomes without differentiation of primarysecondary outcomes. One of the RCTs[15] that was published early used a clear definition of FR that was consistent with that of prior high-quality RCTs; another RCT[17] used a different method of assignment that was in line with investigating the influence of rapid versus slow fluid therapy. Among the 8 included observational studies[14, 16, 18-20, 29-31], 5 studies [14, 18, 19, 29, 31] were assessed as high quality using the modified NOS, and another 3 studies[16, 20,30] were assessed as low quality (Additional file 1 : Table S2). In terms of the therapeutic protocol for the observational studies, 6 studies[14, 18, 20, 29-31] directly defined AFT with a clear FV, but in 2 studies[16, 19], AFT was defined as the use of a percentage of the cumulative 72-h FR within the initial $24 \mathrm{~h}$. However, all of the included observational studies fulfilled the predefined criteria for AFT with a FV of no less than 4,000 ml, except for one trial[19]. Categorization of fluid type seems to be impossible due to the controversial protocol, but most of them selected a crystal solution as the main resuscitation fluid. 
Table 1

Characteristics of included studies.

\begin{tabular}{|c|c|c|c|c|c|c|c|c|}
\hline \multirow[t]{2}{*}{ Study } & \multirow[t]{2}{*}{ Type } & \multicolumn{2}{|c|}{ Patients } & \multicolumn{2}{|c|}{ FV or FR (first 24 h) } & \multirow{2}{*}{$\begin{array}{l}\text { Average } \\
\text { age } \\
\text { (years) }\end{array}$} & \multirow[t]{2}{*}{ Fluid type } & \multirow{2}{*}{$\begin{array}{l}\text { Quality } \\
\text { assessment }\end{array}$} \\
\hline & & AFT & CFT & AFT & CFT & & & \\
\hline $\begin{array}{l}\text { Buxbaum } \\
\text { et al. }{ }^{13}\end{array}$ & RCT & 27 & 33 & $\begin{array}{l}20 \mathrm{ml} / \mathrm{kg} \\
\text { bolus follow } \\
\text { by } 3 \mathrm{ml} / \mathrm{kg} / \mathrm{h}\end{array}$ & $\begin{array}{l}10 \mathrm{ml} / \mathrm{kg} \\
\text { bolus follow } \\
\text { by } 3 \mathrm{ml} / \mathrm{kg} / \mathrm{h}\end{array}$ & $\leq 50$ & LR & High \\
\hline $\begin{array}{l}\text { Cuéllar et } \\
\text { al. }^{28}\end{array}$ & $\mathrm{RCT}$ & 43 & 45 & $\begin{array}{l}20 \mathrm{ml} / \mathrm{kg} \\
\text { follow by } \\
3 \mathrm{ml} / \mathrm{kg} / \mathrm{h}\end{array}$ & $1.5 \mathrm{ml} / \mathrm{kg} / \mathrm{h}$ & $\leq 50$ & $\mathrm{HS}$ & High \\
\hline $\begin{array}{l}\text { De- } \\
\text { Madaria et } \\
\text { al. }^{14}\end{array}$ & $\mathrm{RP}$ & 61 & 63 & $\mathrm{FV}>4.1 \mathrm{~L}$ & $\mathrm{FV}<3.1 \mathrm{~L}$ & $>50$ & $0.9 \% \mathrm{NaCl}, 5-10 \%$ dextrose & High \\
\hline $\begin{array}{l}\text { Gardner et } \\
\text { al. }{ }^{\# 16}\end{array}$ & $\mathrm{R}$ & 17 & 28 & $\begin{array}{l}F V \geq 1 / 3 \text { of } \\
72 \mathrm{~h} \text { total } \mathrm{FV}\end{array}$ & $\begin{array}{l}\mathrm{FV}<1 / 3 \text { of } \\
72 \mathrm{~h} \text { total } \mathrm{FV}\end{array}$ & $>50$ & $\begin{array}{l}0.45-0.9 \% \mathrm{NaCl}, \mathrm{LR}, \\
5 \% \text { dextrose }\end{array}$ & Low \\
\hline Li et al. $\$ 29$ & $\mathrm{RP}$ & 70 & 78 & $\begin{array}{l}\mathrm{FR} \geq \\
3 \mathrm{ml} / \mathrm{kg} / \mathrm{h}\end{array}$ & $\begin{array}{l}\mathrm{FR}< \\
3 \mathrm{ml} / \mathrm{kg} / \mathrm{h}\end{array}$ & $\leq 50$ & $0.9 \% \mathrm{NaCl}, \mathrm{LR}$ & High \\
\hline $\begin{array}{l}\text { Mao et al. } \\
\star 15\end{array}$ & $\mathrm{RCT}$ & 36 & 40 & $\begin{array}{l}10-15 \\
\mathrm{ml} / \mathrm{kg} / \mathrm{h}\end{array}$ & $\begin{array}{l}5-10 \\
\mathrm{ml} / \mathrm{kg} / \mathrm{h}\end{array}$ & $>50$ & $\begin{array}{l}0.9 \% \mathrm{NaCl}, \mathrm{LR} \text {, plasma, } \\
6 \% \text { hydroxyethyl }\end{array}$ & Low \\
\hline $\begin{array}{l}\text { Mao et al. } \\
\star \# 17\end{array}$ & $\mathrm{RCT}$ & 56 & 59 & $\begin{array}{l}\text { Rapid } \\
\text { hemodilution }\end{array}$ & $\begin{array}{l}\text { Slow } \\
\text { hemodilution }\end{array}$ & $\leq 50$ & $\begin{array}{l}0.9 \% \mathrm{NaCl}, \mathrm{LR} \text {, plasma, } \\
6 \% \text { hydroxyethyl }\end{array}$ & Low \\
\hline $\begin{array}{l}\text { Messallam } \\
\text { et al. }{ }^{30}\end{array}$ & $\mathrm{R}$ & 103 & 102 & $\mathrm{FV} \geq 4.475 \mathrm{~L}$ & $\mathrm{FV} \leq 2.8 \mathrm{~L}$ & $\leq 50$ & $0.9 \% \mathrm{NaCl}, \mathrm{LR}$ & Low \\
\hline $\begin{array}{l}\text { Singh et } \\
\text { al. }{ }^{18}\end{array}$ & $\mathrm{R}$ & 256 & 260 & $\mathrm{FV}>4.3 \mathrm{~L}$ & $\mathrm{FV}<3.2 \mathrm{~L}$ & $>50$ & NA & High \\
\hline $\begin{array}{l}\text { Warndorf } \\
\text { et al. } \# 19\end{array}$ & $\mathrm{R}$ & 340 & 94 & $\begin{array}{l}F V \geq 1 / 3 \text { of } \\
72 \mathrm{~h} \text { total } \mathrm{FV}\end{array}$ & $\begin{array}{l}\mathrm{FV}<1 / 3 \text { of } \\
72 \mathrm{~h} \text { total } \mathrm{FV}\end{array}$ & $>50$ & $0.9 \% \mathrm{NaCl}$ et al. & High \\
\hline Wu et al. ${ }^{12}$ & $\mathrm{RCT}$ & 19 & 21 & $\begin{array}{l}20 \mathrm{ml} / \mathrm{kg} \\
\text { follow by } \\
3 \mathrm{ml} / \mathrm{kg} / \mathrm{h}\end{array}$ & $1.5 \mathrm{ml} / \mathrm{kg} / \mathrm{h}$ & $>50$ & $0.9 \% \mathrm{NaCl}, \mathrm{LR}$ & High \\
\hline $\begin{array}{l}\text { Yamashita } \\
\text { et al. }{ }^{20}\end{array}$ & $\mathrm{R}$ & 389 & 708 & $\mathrm{FV} \geq 6 \mathrm{~L}$ & $\mathrm{FV}<6 \mathrm{~L}$ & $>50$ & NA & Low \\
\hline Ye et al. ${ }^{31}$ & $\mathrm{R}$ & 55 & 124 & $\mathrm{FV} \geq 4 \mathrm{~L}$ & $\mathrm{FV}<4 \mathrm{~L}$ & $\leq 50$ & $\begin{array}{l}0.9 \% \mathrm{NaCl}, \mathrm{LR} \text {, albumin, } 5 \% \\
\text { sodium bicarbonate, } 5 \% \\
\text { fructopyranose, } 5 \% \text { fructose }\end{array}$ & High \\
\hline \multicolumn{9}{|c|}{$\begin{array}{l}A F T \text { aggressive fluid therapy, } C F T \text { conservative fluid therapy, } F V \text { fluid volume, } F R \text { fluid rate, } R C T \text { randomized contr } \\
\text { retrospective, } R P \text { retrospective design, prospective data collection. } L R \text { lactated ringer's solution, } H S \text { Hartmann's sol } \\
\text { applicable. }\end{array}$} \\
\hline \multicolumn{9}{|c|}{ ^Overlapping patients were potentially presented in these studies, but different outcomes were displayed as well. } \\
\hline \multicolumn{9}{|c|}{ \#Fluid volume was not display directly, but the cumulative total fluid volume in first 24 hour was higher than 4 L. } \\
\hline \&Fluid rate $\mathrm{n}$ & s lowe & tan 5 & $/ \mathrm{kg} / \mathrm{r}$ & but the cumula & total fluid vo & in furct & hour was higher than $4 \mathrm{~L}$. & \\
\hline
\end{tabular}

\section{Primary Outcome}

Data on in-hospital mortality were extracted from 12 studies[12, 14-20, 28-31] that assessed 3,067 patients (Fig. 2). There was a significant difference between the AFT and CFT groups ( $9.8 \%$ and $7.6 \% ; \mathrm{OR}, 1.66 ; 95 \% \mathrm{Cl}, 1.28-2.16 ; P=0.0001$ ), without significant heterogeneity $(\chi 2=12.24$; degrees of freedom [df], $9 ; P=0.2 ; P, 26 \%)$. The results of the subgroup analysis for average age indicated 
that increased in-hospital mortality was observed with AFT in both the subgroup with average age $\leq 50$ years $(15.6 \%$ and $8.1 \%$; OR, $2.26 ; 95 \% \mathrm{Cl}, 1.38-3.68 ; P=0.001)$ and that with average age $>50$ years $(8.1 \%$ and $7.8 \% ; \mathrm{OR}, 1.46 ; 95 \% \mathrm{Cl}, 1.07-2.00 ; P=0.02)$.

\section{Secondary Outcomes}

Six studies $[12,14,20,28,30,31]$ assessed the renal failure rate in 1,676 cases. Patients in the AFT group suffered renal failure more frequently than those in the CFT group $(19.2 \%$ and $9.3 \%$; OR, 2.38; $95 \% \mathrm{Cl}, 1.78-3.18 ; P<0.00001 ; \mathrm{Fig}$. 3), and the results showed no significant between-study heterogeneity $\left(\chi 2=4.39 ; \mathrm{df}, 5 ; P=0.49 ; P^{2}, 0 \%\right)$. The subgroup analysis of average age $\leq 50$ years $(16.7 \%$ and 7.3\%; OR, 2.35; $\left.95 \% \mathrm{Cl}, 1.26-4.40 ; P=0.008 ; P^{2}, 53 \%\right)$ and average age $>50$ years $(20.0 \%$ and $10.0 \% ; \mathrm{OR}, 2.39 ; 95 \% \mathrm{Cl}, 1.72-3.31$; $P<0.00001 ; P, 0 \%)$ also indicated the disadvantage of AFT.

For pancreatic necrosis, available data extracted from 6 studies $[12,14,16,18,28,31]$ showed a significant difference $(31.9 \%$ and $30.7 \%$; OR, 2.34; $95 \% \mathrm{Cl}, 1.60-3.42 ; P<0.0001 ;$ Fig. 4) without significant between-study heterogeneity $(\chi 2=1.8 ; \mathrm{df}, 5 ; P=0.88 ; P$, $0 \%)$. However, there were limited data assessing pancreatic necrosis for the subgroup analysis of average age $\leq 50$ years, and the difference was not statistically significant $\left(P=0.17 ; P^{2}, 0 \%\right)$. In contrast, the subgroup analysis of average age $>50$ years showed a significant difference $\left(P<0.0001 ; P^{2}, 0 \%\right)$.

Eight studies[12, 14, 16, 18, 19, 28, 30, 31] reporting the incidence of organ failure were analyzed (Additional file 1: Fig. S2). Pooled data did not show a significant difference (12.2\% and $11.3 \%$; OR, $1.56 ; 95 \% \mathrm{Cl}, 0.93-2.61 ; P=0.09 ; P=52 \%$ ), and classification of organ failure in a number of trials was not performed. Additionally, subgroup analysis according to prior settings showed no significant difference $(P=0.14$ and $P=0.49)$. Additionally, pooling the data of 6 studies $[12,16,19,28,30,31]$ that assessed LOS showed no significant difference (WMD, 1.42; $95 \% \mathrm{Cl},-0.26-3.09 ; P=0.1 ; P=92 \%$; Additional file 1: Fig. S3). Similarly, a nonsignificant difference (27.0\% and 36.3\%; OR, 1.16; 95\% Cl, 0.49-2.74; $P=0.74 ; P^{2}=78 \%$; Additional file 1: Fig. S4) was observed when the incidence of persistent SIRS within $24 \mathrm{~h}$ was analyzed independently in 7 studies $[12,13,15-17,19,28]$. The analysis of subgroup differences in LOS and the incidence of persistent SIRS indicated no significant differences.

Pooled data from 6 trials $[12,15,20,28,29,31]$ confirmed a significant disadvantage in the AFT group in terms of the incidence of respiratory failure rate $(53.8 \%$ and $23.4 \%$; $O R, 3.81 ; 95 \% \mathrm{Cl}, 1.76-8.23 ; P=0.0007$; Additional file 1 : Fig. S5) with significant moderate heterogeneity $\left(\chi 2=15.91 ; \mathrm{df}, 5 ; P=0.007 ; P^{2}, 69 \%\right)$. There were not sufficient data to subclassify patients into utilization of mechanical ventilation and suffered respiratory failure separately; therefore, all of the events were decided to be relevant to lung injury, and the data were pooled. Subgroup analysis of average age $>50$ years showed a significant difference $(53.2 \%$ and $20.3 \%$; OR, 4.88; $95 \% \mathrm{Cl}, 3.72-6.4 ; P<0.00001)$ without heterogeneity ( $\left.\chi 2=0.68 ; \mathrm{df}, 2 ; P=0.71 ; P^{2}, 0 \%\right)$. In contrast, there was no significant difference in another subgroup analysis $(P=0.17 ; R, 81 \%)$.

\section{Sensitivity Analysis and Publication Bias}

The sensitivity analysis results are shown in Table 2. The minimum and maximum values of WMD or OR for every outcome are shown after the sensitivity analysis. With respect to the results for mortality, renal failure, pancreatic necrosis, respiratory failure and persistent SIRS within $24 \mathrm{~h}$, omitting 1 study did not change the overall conclusion of this meta-analysis. However, the overall estimates for organ failure (OR, 1.81; 95\% Cl, 1.08-3.02; $\left.P=0.02 ; P^{2}=41 \%\right)$ and LOS (WMD, 2.29; 95\% Cl, 0.52-4.07; $P=0.01 ; P^{2}=$ $92 \%$ ) were changed after omitting the study published by Warndorf et al[19]. In addition, omitting the same trial in the subgroup analysis of average age $>50$ years for persistent SIRS yielded a significant change $(\mathrm{OR}, 2.37 ; 95 \% \mathrm{Cl}, 1.12-5.02 ; P=0.02 ; P=0 \%)$. 
Table 2

Sensitivity analysis comparison of AFT and CFT.

\begin{tabular}{|c|c|c|c|c|c|c|c|c|c|c|c|}
\hline \multirow[t]{2}{*}{ Outcomes } & \multirow{2}{*}{$\begin{array}{l}\text { Omitting } \\
\text { study }\end{array}$} & \multirow{2}{*}{$\begin{array}{l}\text { Studies, } \\
\text { no }\end{array}$} & \multirow{2}{*}{$\begin{array}{l}\text { AFT } \\
\text { Patients, } \\
\text { no }\end{array}$} & \multirow{2}{*}{$\begin{array}{l}\text { CFT } \\
\text { Patients, } \\
\text { no }\end{array}$} & \multirow[t]{2}{*}{ WMD/OR* } & \multirow{2}{*}{$\begin{array}{l}95 \% \\
\mathrm{Cl}\end{array}$} & \multirow{2}{*}{$\begin{array}{l}P \\
\text { value* }\end{array}$} & \multicolumn{4}{|c|}{ Study heterogeneity } \\
\hline & & & & & & & & $x^{2}$ & df & $P$ & $R$ \\
\hline \multicolumn{12}{|c|}{ Primary outcome } \\
\hline \multirow[t]{3}{*}{$\begin{array}{l}\text { In-hospital } \\
\text { mortality }\end{array}$} & $\begin{array}{l}\text { Mao et } \\
\text { al. }^{17}\end{array}$ & 9 & 1327 & 1497 & 1.58 & $\begin{array}{l}1.20- \\
2.08\end{array}$ & 0.001 & 10.77 & 8 & 0.21 & $26 \%$ \\
\hline & $\begin{array}{l}\text { Gardner et } \\
\text { al. }^{16}\end{array}$ & 9 & 1366 & 1528 & 1.74 & $\begin{array}{l}1.33- \\
2.27\end{array}$ & $\langle .0001$ & 9.22 & 8 & 0.32 & $13 \%$ \\
\hline & $\begin{array}{l}\text { Warndorf } \\
\text { et al. }{ }^{19}\end{array}$ & 9 & 1043 & 1462 & 1.74 & $\begin{array}{l}1.33- \\
2.27\end{array}$ & $\langle .0001$ & 9.90 & 8 & 0.27 & $19 \%$ \\
\hline \multicolumn{12}{|c|}{ Secondary outcomes } \\
\hline \multirow[t]{2}{*}{$\begin{array}{l}\text { Renal } \\
\text { failure }\end{array}$} & $\begin{array}{l}\text { Yamashita } \\
\text { et al. }{ }^{20}\end{array}$ & 5 & 248 & 331 & 2.26 & $\begin{array}{l}1.29- \\
3.96\end{array}$ & 0.005 & 4.38 & 4 & 0.36 & $9 \%$ \\
\hline & $\begin{array}{l}\text { Cuéllar et } \\
\text { al. }{ }^{28}\end{array}$ & 5 & 594 & 994 & 2.53 & $\begin{array}{l}1.88- \\
3.41\end{array}$ & <. 0.00001 & 0.97 & 4 & 0.91 & $0 \%$ \\
\hline \multirow[t]{2}{*}{$\begin{array}{l}\text { Pancreatic } \\
\text { necrosis }\end{array}$} & $\begin{array}{l}\text { Singh et } \\
\text { al. }^{18}\end{array}$ & 5 & 195 & 281 & 1.93 & $\begin{array}{l}1.02- \\
3.64\end{array}$ & 0.04 & 1.11 & 4 & 0.89 & $0 \%$ \\
\hline & $\begin{array}{l}\text { Gardner et } \\
\text { al. }{ }^{16}\end{array}$ & 5 & 434 & 513 & 2.48 & $\begin{array}{l}1.66- \\
3.70\end{array}$ & <. 0.00001 & 1.02 & 4 & 0.91 & $0 \%$ \\
\hline \multirow[t]{2}{*}{$\begin{array}{l}\text { Organ } \\
\text { failure }\end{array}$} & Ye et al. ${ }^{31}$ & 7 & 839 & 613 & 1.36 & $\begin{array}{l}0.79- \\
2.37\end{array}$ & 0.27 & 10.83 & 6 & 0.09 & $45 \%$ \\
\hline & $\begin{array}{l}\text { Warndorf } \\
\text { et al. }{ }^{\# 19}\end{array}$ & 7 & 554 & 643 & 1.81 & $\begin{array}{l}1.08- \\
3.02\end{array}$ & 0.02 & 10.09 & 6 & 0.12 & $41 \%$ \\
\hline \multirow[t]{2}{*}{ LOS, d } & Ye et al. ${ }^{31}$ & 5 & 376 & 143 & 0.12 & $\begin{array}{l}-0.82- \\
1.05\end{array}$ & 0.81 & 13.17 & 4 & 0.01 & $70 \%$ \\
\hline & $\begin{array}{l}\text { Warndorf } \\
\text { et al. }{ }^{19}\end{array}$ & 5 & 237 & 320 & 2.29 & $\begin{array}{l}0.52- \\
4.07\end{array}$ & 0.01 & 51.97 & 4 & $\hat{0}_{0.00001}$ & $92 \%$ \\
\hline \multirow[t]{2}{*}{ SIRS } & $\begin{array}{l}\text { Mao et } \\
\text { al. }{ }^{17}\end{array}$ & 6 & 482 & 261 & 0.97 & $\begin{array}{l}0.39- \\
2.44\end{array}$ & 0.95 & 19.44 & 5 & 0.002 & $74 \%$ \\
\hline & $\begin{array}{l}\text { Warndorf } \\
\text { et al. }{ }^{19}\end{array}$ & 6 & 198 & 226 & 1.65 & $\begin{array}{l}0.86- \\
3.16\end{array}$ & 0.13 & 8.21 & 5 & 0.14 & $39 \%$ \\
\hline \multirow[t]{2}{*}{$\mathrm{RF}$} & Li et al. ${ }^{29}$ & 5 & 542 & 938 & 3.02 & $\begin{array}{l}1.45- \\
6.29\end{array}$ & 0.003 & 11.62 & 4 & 0.02 & $66 \%$ \\
\hline & $\begin{array}{l}\text { Cuéllar et } \\
\text { al. }{ }^{28}\end{array}$ & 5 & 569 & 971 & 4.87 & $\begin{array}{l}2.38- \\
9.98\end{array}$ & $\langle .0001$ & 9.59 & 4 & 0.05 & $58 \%$ \\
\hline \multirow{3}{*}{\multicolumn{12}{|c|}{$\begin{array}{l}\text { AFT aggressive fluid therapy, CFT conservative fluid therapy, WMD/OR weight mean d } \\
d f \text { degrees of freedom, } L O S \text { length of hospital stay, } d \text { day, SIRS systemic inflammatory } \\
\text { *Minimum and maximum value of WMD or OR of every outcome are shown after the s } \\
\text { ※Statistically significance results were shown in bold. }\end{array}$}} \\
\hline & & & & & & & & & & & \\
\hline & & & & & & & & & & & \\
\hline \multicolumn{12}{|c|}{ \#Compared to the initial results for the organ failure and LOS, significant differences were changed after sensitivity analysis. } \\
\hline
\end{tabular}

The publication bias for reporting in-hospital morality in this meta-analysis is shown in Fig. 5. There was no obvious publication bias, with a homogeneous distribution around the vertical direction, and the $95 \% \mathrm{Cl}$ included all of the included trials. 


\section{Quality of Evidence}

The GRADE system was used to rate the level of evidence by study type: RCT and observational (Additional file 1: Table S3 and Table S4). For the RCTs, there was only one outcome that assessed in-hospital mortality, and the rating was high. The evidence for each of the following outcomes was rated as moderate: incidence of renal failure, pancreatic necrosis, and respiratory failure. The remaining evidences of outcomes for persistent SIRS, organ failure and LOS were rated as low to very low. For the observational studies, there were two evidences for renal failure and pancreatic necrosis were rated as moderate, and the remaining evidences were rated as low to very low.

\section{Discussion}

In this meta-analysis of 13 trials incorporating 3,127 patients, treatment with AFT compared with CFT indicated a significant disadvantage in terms of in-hospital mortality, renal failure and pancreatic necrosis with relatively strong evidence. Additionally, the incidence of respiratory failure seems to be higher in the AFT subgroup with average age $>50$ years. In the sensitivity analysis, omitting one study at a time yielded no significant change in the above outcomes with the remaining studies.

Simultaneously, we found no significant difference in organ failure, persistent SIRS within $24 \mathrm{~h}$ or LOS; however, pooled estimates from the sensitivity analysis were changed after excluding the study conducted by Warndorf et al[19]. Although this study fulfilled the inclusion criteria and the risk of bias assessment indicated that the study was high quality, there were several potential factors relevant to the statistical alteration. Two important differences displayed in this study were an FV less than 4,000 ml and unbalanced sample sizes in both study arms. In addition, the calculated standard deviation of LOS may not be normally distributed. As a result, if the factors were indeed shown, a significant difference in estimates for organ failure and persistent SIRS could be found, and AFT was potentially related to the increased incidence of organ failure and persistent SIRS in the subgroup of patients aged $>50$ years. Nevertheless, the LOS data remained inconclusive, possibly due to the nonnormal distribution published by two other studies[16, 30].

In the evolution of AP, there are multiple factors, including vomiting, fluid loss in the third space, and reduced oral intake, that could induce hypovolemia. Following the progression of hypovolemia, pancreatic microcirculation could be disturbed, with the result being the release of multiple inflammatory cytokines and pancreatic ischemia and multisystem organ failure. Therefore, improved splanchnic hypovolemia and inhibition of the early inflammatory cascade are the fundamental goals of AFT. In particular, the study published by Buxbaum et al.[13] showed obvious clinical improvement and a decreased incidence of persistent SIRS in the AFT group. However, these findings should be viewed with caution due to the limited or unbalanced sample sizes and the mild severity of AP.

Broader implementation of aggressive fluid treatment should be more cautious according to this meta-analysis. The recommendations for AFT from previous guidelines $[5,6]$ were mainly based on observational trials, expert opinions and experimental findings. A number of studies[12,13,16,19] reported important outcomes in line with the recommendations in recent years. However, AFT is commonly accompanied by visceral edema[32] and excessive chloride[33], which may contribute to intra-abdominal hypertension and impaired renal function, and both of these results can affect each other simultaneously[34, 35]. In addition, rapidly increasing intravenous volume did not change oxygen delivery and oxygen consumption, even though cardiac output was remarkably improved[36]. This type of pathological event might be caused by the hemodilution-induced decrease in hematocrit, which was noted as a risk factor the development of organ failure and pancreatic necrosis[37]. Therefore, clinical advocation for CFT has received general attention because of the non-neglectful improvements in pulmonary/renal failure, pancreatic necrosis, and mortality $[15,17,18,29,31,38,39]$. Adverse events, which decreased as described above, are potentially related to prior underlying pathology, and the study reported by Warndorf et al[19] might be the best proof of this. Overall, given the estimated homogeneity and significant of the results, our findings strengthen the hypothesis that CFT is not inferior to AFT.

Since the first meta-analysis on aggressive fluid resuscitation for AP by Gad et al.[24], additional evidence to support the benefit of fluid therapy has not been reported, even though the report indicated potential inferiority of AFT without exact statistical significance. Although we agree with the standpoints from the study, some deficiencies remain that are worthy of attention. First, a lower fluid rate threshold of $3-5 \mathrm{ml} / \mathrm{kg} / \mathrm{h}$ in the first $24 \mathrm{~h}$ was defined as aggressive fluid resuscitation, which was inconsistent and not specific to prior guidelines[5] that declared aggressive FR as being higher than $10 \mathrm{ml} / \mathrm{kg} / \mathrm{h}$ or FV as being higher than $4000 \mathrm{ml}$ within $24 \mathrm{~h}$. More than two-thirds of the included studies were observational studies, which means that is impossible to refine an immutable FV to an 
exact FR per hour per kilogram. Second, the included studies enrolled two potentially overlapping trials published by Buxbaum et al. $[13,40]$ and Mao et al. $[15,17]$ without definite reason. Exaggerative outcomes were possibly generated due to this deficiency. Third, for the meta-analysis of SIRS, data were extracted without differentiation of the stage prior to and posttreatment. The study tried to analyze the influence of fluid therapy; however, data[14,31] extracted from the stage prior to treatment should not be regarded as the therapeutic effect. Consequently, our group was motivated to further investigate the benefit of fluid therapy.

The following limitations of our meta-analysis should be taken into account. The main limitation is that more than half of the included trials were observational studies, and the remaining 5 RCTs were conducted with small sample sizes. Although in-hospital mortality is unlikely to be influenced by a lack of blinding[41] due to the complex dynamic evaluation, this evidence, which was rated as having a high risk of bias, should be interpreted with caution due to the small-study effect[42]. The subgroup analysis yielded some significant outcomes compared to the original analysis, indicating unstable endpoints because of a specific study. In addition, most of the present studies did not separate the severity of AP to investigate the benefit of AFT versus CFT. Some previous studies[43-45] suggested that the type of fluid also played an important role in the prognosis of pancreatitis; however, our research could not completely distinguish the types of liquids used and perform a subgroup analysis. Future systematic analyses should evaluate the severity of AP and fluid type when sufficient data are available.

Overall, this meta-analysis is the first report of the disadvantage of AFT and found a timely, conclusive outcome as data have accumulated and become available for inspection by meta-analytical theory. A broad strategy was used to identify eligible studies to increase the sensitivity of the study. Detailed sensitivity and subgroup analysis were performed to minimize the heterogeneity of every outcome. Therefore, up-to-date information was provided in our research.

\section{Conclusion}

In adults with AP, compared with $\mathrm{CFT}, \mathrm{AFT}$ is associated with increased in-hospital mortality and an increased incidence of renal failure and pancreatic necrosis. In patients with an average age $>50$ years, AFT is potentially related to an increase in the incidence of respiratory failure. Meanwhile, the increase in persistent organ failure and SIRS within $24 \mathrm{~h}$ is potentially influenced by controversial practices. Nevertheless, several limitations presented above prevent us from drawing definitive conclusions. Further well-designed, properly powered trials will be required to confirm and update the findings of this meta-analysis.

\section{Abbreviations}

AFT: aggressive fluid treatment; CFT: conservative fluid treatment; AP: acute pancreatitis; RCT: randomized control trial; PRISMA: Preferred Reporting Items for Systematic Reviews and Meta-analyses; FR: fluid rate; FV: fluid volume; ERCP: endoscopic retrograde cholangiopancreatography; SIRS: systemic inflammatory response syndrome; LOS: length of hospital stay; GRADE: Grading of Recommendations Assessment, Development, and Evaluation; NOS: Newcastle-Ottawa scale; OR: odds ratio; WMD: weighted mean difference; Cl: confidence intervals. SD: standard deviations.

\section{Declarations}

Ethics approval and consent to participate: Not applicable.

Consent for publication: Not applicable.

Availability of data and materials: All data generated or analysed during this study are included in this published article and its supplementary information files.

Competing interests: The authors declare that they have no competing interests.

Funding: Not applicable.

Authors' contributions: JYL, YZ and JBL contributed to the study conception and design. Literature search, data collection and analysis were performed by YZ, HCW and XP. The first draft and review of the manuscript was prepared by JYL and YZ. Supervision, material support and project administration were performed by JBL and ZJY. All authors commented on previous versions of the manuscript. All authors read and approved the final manuscript.

Page 9/15 
Acknowledgements: Not applicable.

\section{References}

1. van Santvoort HC, Bakker OJ, Bollen TL, Besselink MG, Ahmed Ali U, Schrijver AM, Boermeester MA, van Goor $\mathrm{H}$, Dejong $\mathrm{CH}$, van Eijck $\mathrm{CH}$, et al. A conservative and minimally invasive approach to necrotizing pancreatitis improves outcome. Gastroenterology. 2011;141(4):1254-63.

2. Banks PA, Bollen TL, Dervenis C, Gooszen HG, Johnson CD, Sarr MG, Tsiotos GG, Vege SS. Acute Pancreatitis Classification Working G: Classification of acute pancreatitis-2012: revision of the Atlanta classification and definitions by international consensus. Gut. 2013;62(1):102-11.

3. Garg PK, Singh VP. Organ Failure Due to Systemic Injury in Acute Pancreatitis. Gastroenterology. 2019;156(7):2008-23.

4. Tenner S, Baillie J, DeWitt J, Vege SS, American College of G: American College of Gastroenterology guideline: management of acute pancreatitis. The American journal of gastroenterology 2013, 108(9):1400-1415; 1416.

5. Working Group IAPAPAAPG. IAP/APA evidence-based guidelines for the management of acute pancreatitis. Pancreatology: official journal of the International Association of Pancreatology (IAP) [et al]. 2013;13(4 Suppl 2):e1-15.

6. Leppaniemi A, Tolonen M, Tarasconi A, Segovia-Lohse H, Gamberini E, Kirkpatrick AW, Ball CG, Parry N, Sartelli M, Wolbrink D, et al. 2019 WSES guidelines for the management of severe acute pancreatitis. World journal of emergency surgery: WJES. 2019;14:27.

7. Gardner TB, Vege SS, Pearson RK, Chari ST. Fluid resuscitation in acute pancreatitis. Clinical Gastroenterology Hepatology. 2008;6(10):1070-6.

8. Tenner S. Initial management of acute pancreatitis: critical issues during the first 72 hours. Am J Gastroenterol. 2004;99(12):2489-94.

9. Bassi D, Kollias N, Fernandez-del Castillo C, Foitzik T, Warshaw AL, Rattner DW. Impairment of pancreatic microcirculation correlates with the severity of acute experimental pancreatitis. J Am Coll Surg. 1994;179(3):257-63.

10. Kerner T, Vollmar B, Menger MD, Waldner H, Messmer K. Determinants of pancreatic microcirculation in acute pancreatitis in rats. J Surg Res. 1996;62(2):165-71.

11. Wall I, Badalov N, Baradarian R, Iswara K, Li JJ, Tenner S. Decreased mortality in acute pancreatitis related to early aggressive hydration. Pancreas. 2011;40(4):547-50.

12. Wu BU, Hwang JQ, Gardner TH, Repas K, Delee R, Yu S, Smith B, Banks PA, Conwell DL. Lactated Ringer's Solution Reduces Systemic Inflammation Compared With Saline in Patients With Acute Pancreatitis. Clin Gastroenterol Hepatol. 2011;9(8):710U127.

13. Buxbaum JL, Quezada M, Da B, Jani N, Lane C, Mwengela D, Kelly T, Jhun P, Dhanireddy K, Laine L. Early Aggressive Hydration Hastens Clinical Improvement in Mild Acute Pancreatitis. Am J Gastroenterol. 2017;112(5):797-803.

14. de-Madaria E, Soler-Sala G, Sanchez-Paya J, Lopez-Font I, Martinez J, Gomez-Escolar L, Sempere L, Sanchez-Fortun C, PerezMateo M. Influence of Fluid Therapy on the Prognosis of Acute Pancreatitis: A Prospective Cohort Study. Am J Gastroenterol. 2011;106(10):1843-50.

15. En-Qiang M, Yao-Qing T, Jian F, Shuai Q, Jun W, Lei L, Dong M, Sheng-Dao Z. Fluid therapy for severe acute pancreatitis in acute response stage. Chin Med J. 2009;122(2):169-73.

16. Gardner TB, Vege SS, Chari ST, Petersen BT, Topazian MD, Clain JE, Pearson RK, Levy MJ, Sarr MG: Faster Rate of Initial Fluid Resuscitation in Severe Acute Pancreatitis Diminishes In-Hospital Mortality. Pancreatology: official journal of the International Association of Pancreatology (IAP) [et al] 2009, 9(6):770-776.

17. Mao EQ, Fei J, Peng YB, Huang J, Tang YQ, Zhang SD. Rapid hemodilution is associated with increased sepsis and mortality among patients with severe acute pancreatitis. Chin Med J. 2010;123(13):1639-44.

18. Singh VK, Gardner TB, Papachristou GI, Rey-Riveiro M, Faghih M, Koutroumpakis E, Afghani E, Acevedo-Piedra NG, Seth N, Sinha $A$, et al. An international multicenter study of early intravenous fluid administration and outcome in acute pancreatitis. United European gastroenterology journal. 2017;5(4):491-8.

19. Warndorf MG, Kurtzman JT, Bartel MJ, Cox M, Mackenzie T, Robinson S, Burchard PR, Gordon SR, Gardner TB. Early Fluid Resuscitation Reduces Morbidity Among Patients With Acute Pancreatitis. Clin Gastroenterol Hepatol. 2011;9(8):705-9.

Page 10/15 
20. Yamashita T, Horibe M, Sanui M, Sasaki M, Sawano H, Goto T, Ikeura T, Hamada T, Oda T, Yasuda H, et al. Large Volume Fluid Resuscitation for Severe Acute Pancreatitis is Associated With Reduced Mortality A Multicenter Retrospective Study. Journal of clinical gastroenterology. 2019;53(5):385-91.

21. Brown A, Baillargeon JD, Hughes MD, Banks PA. Can fluid resuscitation prevent pancreatic necrosis in severe acute pancreatitis? Pancreatology: official journal of the International Association of Pancreatology (IAP) [et al]. 2002;2(2):104-7.

22. Eckerwall G, Olin $\mathrm{H}$, Andersson $B$, Andersson R. Fluid resuscitation and nutritional support during severe acute pancreatitis in the past: what have we learned and how can we do better? Clin Nutr. 2006;25(3):497-504.

23. Muddana V, Whitcomb DC, Khalid A, Slivka A, Papachristou GI. Elevated serum creatinine as a marker of pancreatic necrosis in acute pancreatitis. Am J Gastroenterol. 2009;104(1):164-70.

24. Gad MM, Simons-Linares CR. Is aggressive intravenous fluid resuscitation beneficial in acute pancreatitis? A meta-analysis of randomized control trials and cohort studies. World journal of gastroenterology. 2020;26(10):1098-106.

25. Liberati A, Altman DG, Tetzlaff J, Mulrow C, Gotzsche PC, loannidis JP, Clarke M, Devereaux PJ, Kleijnen J, Moher D. The PRISMA statement for reporting systematic reviews and meta-analyses of studies that evaluate healthcare interventions: explanation and elaboration. BMJ. 2009;339:b2700.

26. Guyatt GH, Oxman AD, Vist GE, Kunz R, Falck-Ytter Y, Alonso-Coello P, Schunemann HJ, Group GW. GRADE: an emerging consensus on rating quality of evidence and strength of recommendations. BMJ. 2008;336(7650):924-6.

27. Hozo SP, Djulbegovic B, Hozo I. Estimating the mean and variance from the median, range, and the size of a sample. BMC Med Res Methodol. 2005;5:13.

28. Cuéllar-Monterrubio JE, Monreal-Robles R, González-Moreno El, Borjas-Almaguer OD, Herrera-Elizondo JL, García-Compean D, Maldonado-Garza HJ, González-González JA. Nonaggressive Versus Aggressive Intravenous Fluid Therapy in Acute Pancreatitis With More Than 24 Hours From Disease Onset: A Randomized Controlled Trial. Pancreas. 2020;49(4):579-83.

29. Li L, Jin T, Wen S, Shi N, Zhang RW, Zhu P, Lin ZQ, Jiang K, Guo J, Liu TT, et al. Early Rapid Fluid Therapy Is Associated with Increased Rate of Noninvasive Positive-Pressure Ventilation in Hemoconcentrated Patients with Severe Acute Pancreatitis. Digestive diseases sciences. 2020;65(9):2700-11.

30. Messallam AA, Body CB, Berger S, Sakaria SS, Chawla S. Impact of early aggressive fluid resuscitation in acute pancreatitis. Pancreatology: official journal of the International Association of Pancreatology (IAP) [et al]. 2021;21(1):69-73.

31. Ye B, Mao WJ, Chen YH, Tong ZH, Li G, Zhou J, Ke L, Li WQ. Aggressive Resuscitation Is Associated with the Development of Acute Kidney Injury in Acute Pancreatitis. Digestive diseases sciences. 2019;64(2):544-52.

32. Tsai YC, Tsai JC, Chen SC, Chiu YW, Hwang SJ, Hung CC, Chen TH, Kuo MC, Chen HC. Association of fluid overload with kidney disease progression in advanced CKD: a prospective cohort study. Am J Kidney Dis. 2014;63(1):68-75.

33. Yunos NM, Bellomo R, Hegarty C, Story D, Ho L, Bailey M. Association between a chloride-liberal vs chloride-restrictive intravenous fluid administration strategy and kidney injury in critically ill adults. Jama. 2012;308(15):1566-72.

34. Cheatham ML, Malbrain ML, Kirkpatrick A, Sugrue M, Parr M, De Waele J, Balogh Z, Leppaniemi A, Olvera C, Ivatury R, et al: Results from the International Conference of Experts on Intra-abdominal Hypertension and Abdominal Compartment Syndrome. II. Recommendations. Intensive care medicine 2007, 33(6):951-962.

35. Dalfino L, Tullo L, Donadio I, Malcangi V, Brienza N. Intra-abdominal hypertension and acute renal failure in critically ill patients. Intensive care medicine. 2008;34(4):707-13.

36. Monnet X, Julien F, Ait-Hamou N, Lequoy M, Gosset C, Jozwiak M, Persichini R, Anguel N, Richard C, Teboul JL. Lactate and venoarterial carbon dioxide difference/arterial-venous oxygen difference ratio, but not central venous oxygen saturation, predict increase in oxygen consumption in fluid responders. Critical care medicine. 2013;41(6):1412-20.

37. Brown A, Orav J, Banks PA. Hemoconcentration is an early marker for organ failure and necrotizing pancreatitis. Pancreas. 2000;20(4):367-72.

38. Parniczky A, Kui B, Szentesi A, Balazs A, Szucs A, Mosztbacher D, Czimmer J, Sarlos P, Bajor J, Godi S, et al. Prospective, Multicentre, Nationwide Clinical Data from 600 Cases of Acute Pancreatitis. PloS one. 2016;11(10):e0165309.

39. Weitz G, Woitalla J, Wellhöner P, Schmidt K, Büning J, Fellermann K. Detrimental effect of high volume fluid administration in acute pancreatitis - a retrospective analysis of 391 patients. Pancreatology: official journal of the International Association of Pancreatology (IAP) [et al]. 2014;14(6):478-83. 
40. Buxbaum J, Mwengela D, Jani N, Kelly T, Dhanireddy K, Nneji J, Jhun P. Randomized trial of moderate versus aggressive fluid therapy in patients with mild to moderate acute pancreatitis. Pancreas. 2014;43(8):1346.

41. Savovic J, Jones HE, Altman DG, Harris RJ, Juni P, Pildal J, Als-Nielsen B, Balk EM, Gluud C, Gluud LL, et al. Influence of reported study design characteristics on intervention effect estimates from randomized, controlled trials. Ann Intern Med.

2012;157(6):429-38.

42. Zhang Z, Xu X, Ni H. Small studies may overestimate the effect sizes in critical care meta-analyses: a meta-epidemiological study. Crit Care. 2013;17(1):R2.

43. Aboelsoud MM, Siddique O, Morales A, Seol Y, Al-Qadi MO. Fluid Choice Matters in Critically-ill Patients with Acute Pancreatitis: Lactated Ringer's vs. Isotonic Saline. R I Med. 2016;99(10):39-42.

44. Choosakul S, Harinwan K, Chirapongsathorn S, Opuchar K, Sanpajit T, Piyanirun W, Puttapitakpong C. Comparison of normal saline versus Lactated Ringer's solution for fluid resuscitation in patients with mild acute pancreatitis, A randomized controlled trial. Pancreatology: official journal of the International Association of Pancreatology (IAP) [et al]. 2018;18(5):507-12.

45. De-Madaria E, Gonzalez-Camacho V, Herrera-Marante I, Quesada-Vazquez N, Sanchez-Marin C, Moreu-Martin R. Lactated Ringers Solution Versus Normal Saline for Fluid Resuscitation in Acute Pancreatitis, a Randomized Controlled Trial. Gastroenterology. 2016;150(4):65-5.

46. Additional file 1.

\section{Figures}

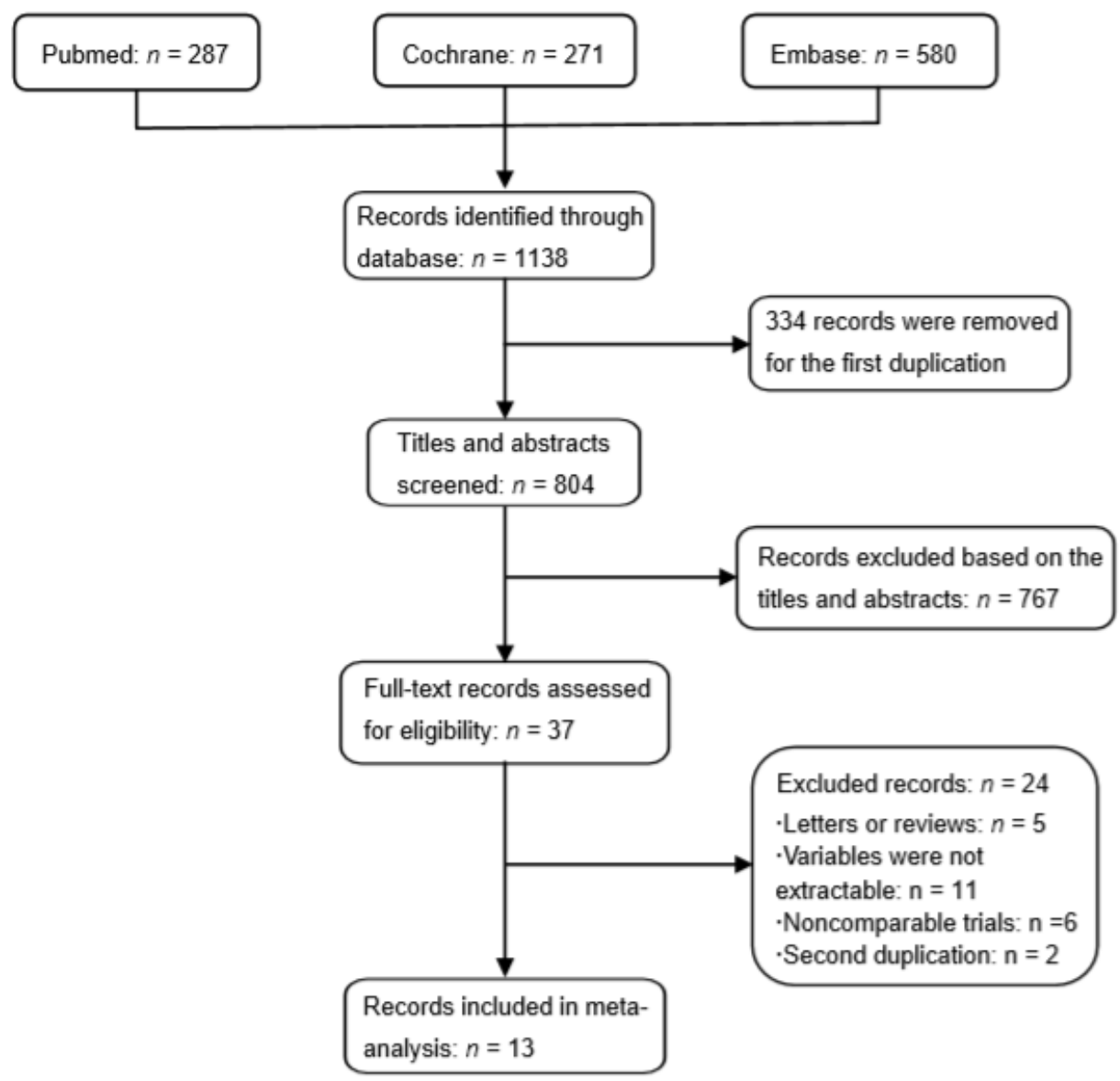

\section{Figure 1}

PRISMA flow diagram showing inclusion and exclusion of studies. 
Aggressive Conservative Odds Ratio Odds Ratio

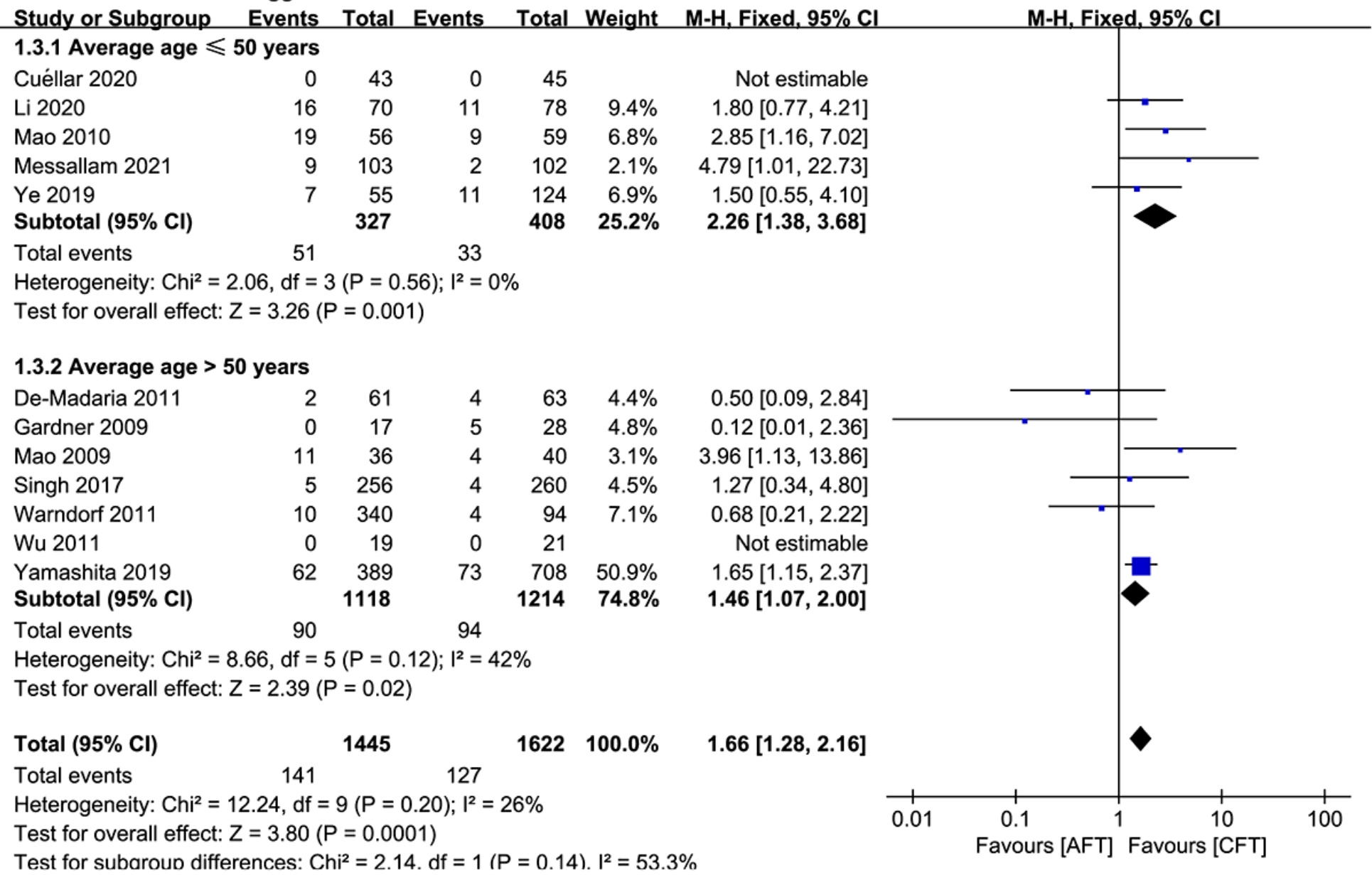

Figure 2

Forest plot and meta-analysis of in-hospital mortality; Cl confidence interval, M-H Mantel-Haenszel, AFT aggressive fluid therapy, CFT conservative fluid therapy 
aggressive conservative Odds Ratio

M-H, Fixed, $95 \% \mathrm{Cl}$

Odds Ratio

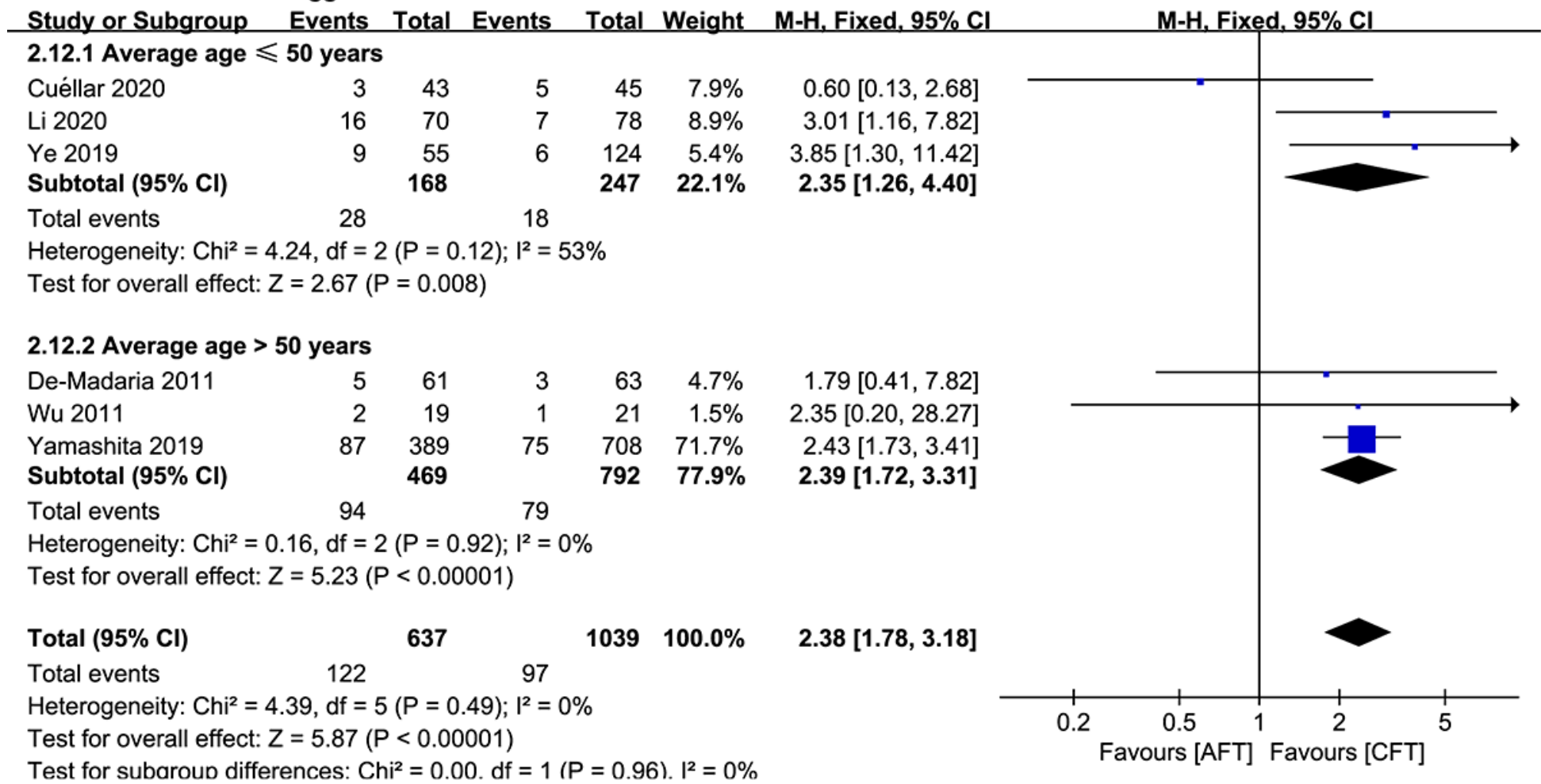

Figure 3

Forest plot and meta-analysis of renal failure; Cl confidence interval; M-H Mantel-Haenszel, AFT aggressive fluid therapy, CFT conservative fluid therapy

\section{aggressive conservative Odds Ratio}

Odds Ratio

Study or Subgroup Events Total Events Total Weight $\mathrm{M}-\mathrm{H}$, Fixed, $95 \% \mathrm{Cl}$

2.13.1 Average age $\leqslant 50$ years

$\begin{array}{lrrrrrr}\text { Cuéllar 2020 } & 4 & 43 & 3 & 45 & 7.3 \% & 1.44[0.30,6.83] \\ \text { Ye 2019 } & 54 & 55 & 115 & 124 & 3.5 \% & 4.23[0.52,34.21] \\ \text { Subtotal (95\% CI) } & & \mathbf{9 8} & & \mathbf{1 6 9} & \mathbf{1 0 . 8 \%} & \mathbf{2 . 3 4}[\mathbf{0 . 7 0}, \mathbf{7 . 8 2}] \\ \text { Total events } & 58 & & 118 & & & \end{array}$

Heterogeneity: $\mathrm{Chi}^{2}=0.68, \mathrm{df}=1(\mathrm{P}=0.41) ; \mathrm{I}^{2}=0 \%$

Test for overall effect: $Z=1.39(P=0.17)$

2.13.2 Average age $>\mathbf{5 0}$ years

$\begin{array}{lrrrrrr}\text { De-Madaria 2011 } & 12 & 61 & 7 & 63 & 15.1 \% & 1.96[0.72,5.37] \\ \text { Gardner 2009 } & 8 & 17 & 11 & 28 & 12.0 \% & 1.37[0.41,4.64] \\ \text { Singh 2017 } & 65 & 256 & 30 & 260 & 60.8 \% & 2.61[1.63,4.19] \\ \text { Wu 2011 } & 1 & 19 & 0 & 21 & 1.2 \% & 3.49[0.13,90.86] \\ \text { Subtotal (95\% CI) } & & \mathbf{3 5 3} & & \mathbf{3 7 2} & \mathbf{8 9 . 2 \%} & \mathbf{2 . 3 4}[\mathbf{1 . 5 7}, \mathbf{3 . 4 9}]\end{array}$

Total events $86 \quad 48$

Heterogeneity: $\mathrm{Chi}^{2}=1.12, \mathrm{df}=3(\mathrm{P}=0.77) ; \mathrm{I}^{2}=0 \%$

Test for overall effect: $Z=4.18(P<0.0001)$

Total $(95 \% \mathrm{Cl})$

Total events

Heterogeneity: $\mathrm{Chi}^{2}=1.80, \mathrm{df}=5(\mathrm{P}=0.88) ; \mathrm{I}^{2}=0 \%$

Test for overall effect: $Z=4.40(P<0.0001)$

Test for subaroun differences: $\mathrm{Chi}^{2}=0.00 . \mathrm{df}=1(\mathrm{P}=1.00) . \mathrm{I}^{2}=0 \%$

\section{$\mathrm{M}-\mathrm{H}$, Fixed, $95 \% \mathrm{Cl}$}

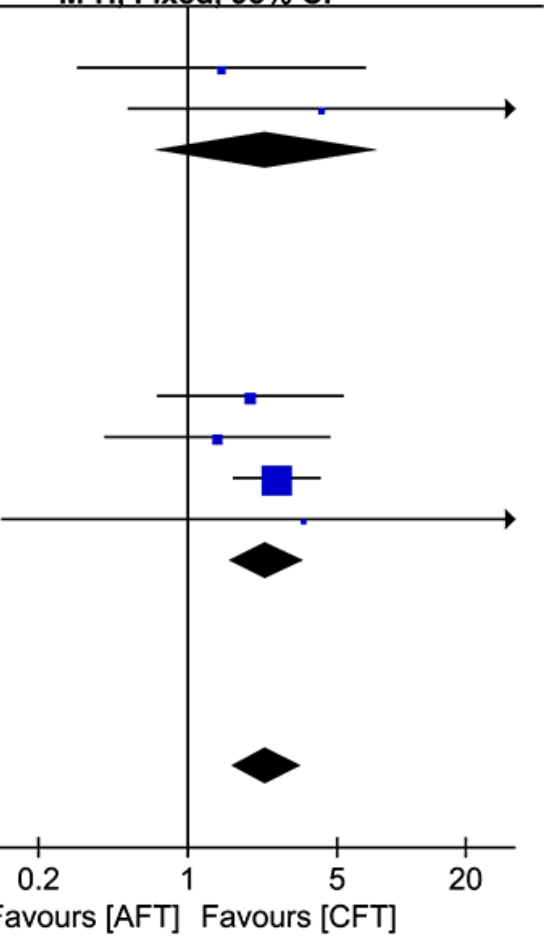

Figure 4 
Forest plot and meta-analysis of pancreatic necrosis; Cl confidence interval, M-H Mantel-Haenszel, AFT aggressive fluid therapy, CFT conservative fluid therapy

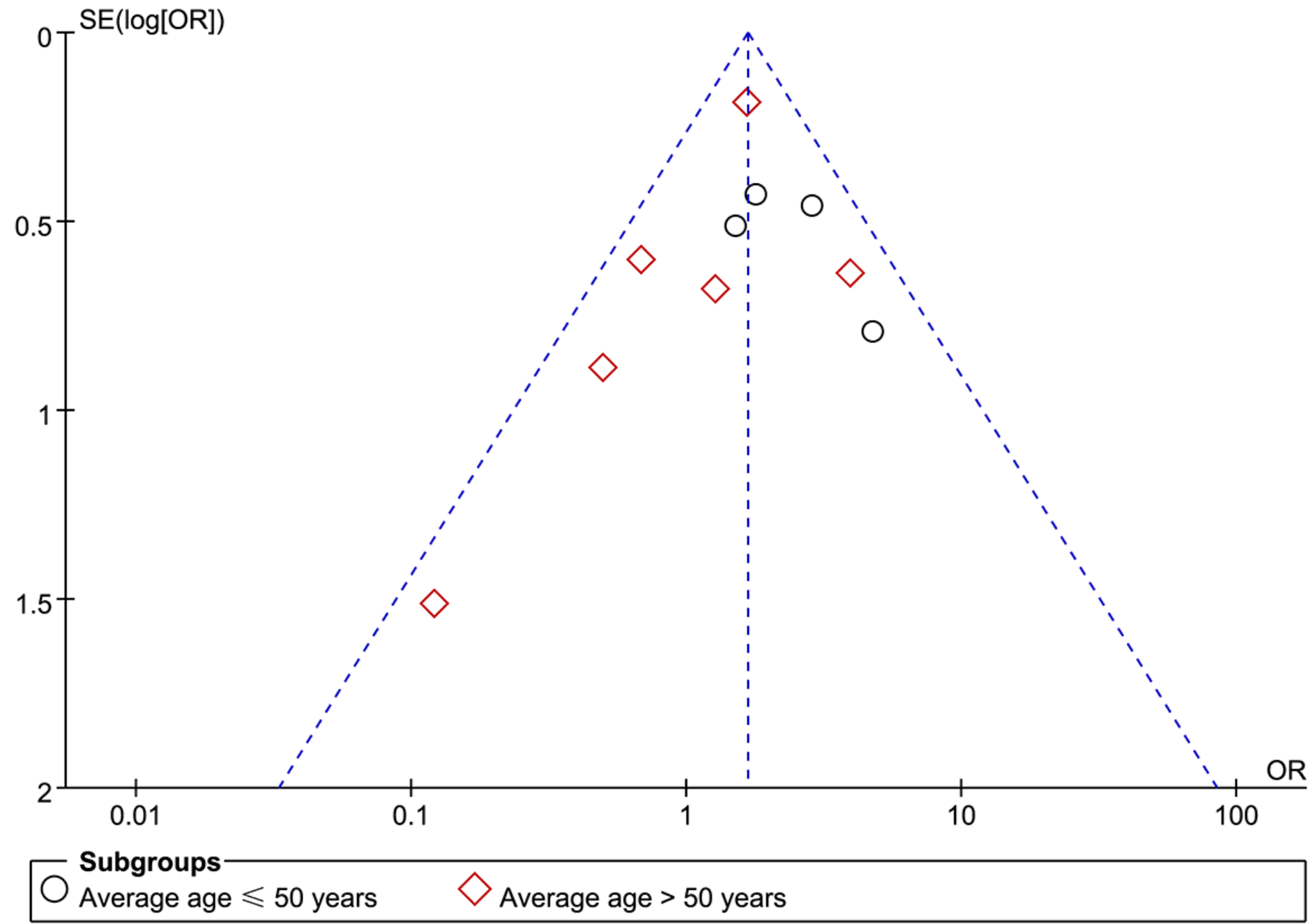

Figure 5

Funnel plot illustrating analysis of in-hospital mortality; SE standard error, OR odds ratio

\section{Supplementary Files}

This is a list of supplementary files associated with this preprint. Click to download.

- Additionalfile1figure.pdf

- TableS1.docx

- Tables2.docx

- TableS3.docx

- Tables4.docx 